\title{
Erratum to: Clinical Investigations in Gastroenterology
}

Erratum to: 3

M.C. Bateson, I.A.D. Bouchier, Clinical Investigations in Gastroenterology, $\quad 4$ DOI 10.1007/978-3-319-53786-3 5

DOI 10.1007/978-3-319-53786-3_17 8

9

We received following corrections from author after publication of this book. 11

Hereditary non-polyposis colon cancer was wrongly abbreviated as HPNCC in sub 13 section 8.8.4 in page 100. The abbreviation was corrected to HNPCC. 14

In Table12.2, page 149, 5th row was changed to HBeAg instead of HBsAg. 16

The updated original online version of the chapters can be found under 17 DOI 10.1007/978-3-319-53786-3_8

DOI 10.1007/978-3-319-53786-3_12 19 


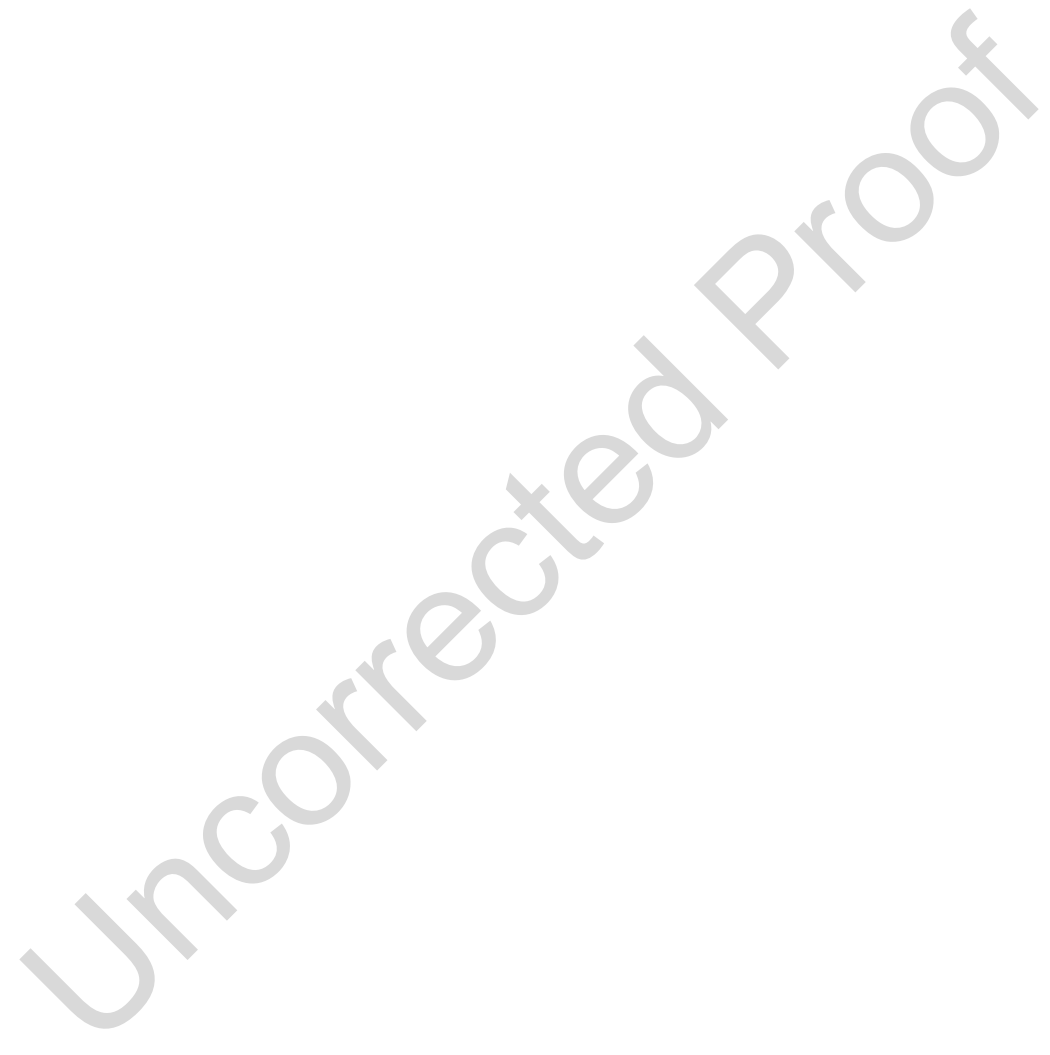

